\title{
Arthrospira platensis Extract: A Non-Invasive Strategy to Obtain Adjunct Attenuated Cultures
}

\author{
Elena Bancalari *(D), Francesco Martelli ${ }^{D}$, Benedetta Bottari $\mathbb{D}^{\text {, }}$, Erasmo Neviani ${ }^{(D)}$ and Monica Gatti \\ Department of Food and Drug, University of Parma, Parco Area delle Scienze 49/A, 43124 Parma, Italy; \\ francesco.martelli@unipr.it (F.M.); benedetta.bottari@unipr.it (B.B.); erasmo.neviani@unipr.it (E.N.); \\ monica.gatti@unipr.it (M.G.) \\ * Correspondence: elena.bancalari@unipr.it
}

Citation: Bancalari, E.; Martelli, F.; Bottari, B.; Neviani, E.; Gatti, M. Arthrospira platensis Extract: A Non-Invasive Strategy to Obtain Adjunct Attenuated Cultures. Foods 2021, 10, 588. https://doi.org/ $10.3390 /$ foods 10030588

Academic Editors: Giovanna Felis and Elisa Salvetti

Received: 3 February 2021

Accepted: 9 March 2021

Published: 11 March 2021

Publisher's Note: MDPI stays neutral with regard to jurisdictional claims in published maps and institutional affiliations.

Copyright: (c) 2021 by the authors. Licensee MDPI, Basel, Switzerland. This article is an open access article distributed under the terms and conditions of the Creative Commons Attribution (CC BY) license (https:// creativecommons.org/licenses/by/ $4.0 /)$.

\begin{abstract}
This study aims at proposing the use of Arthrospira platensis, commonly known as Spirulina, extract as a non-invasive method to attenuate the growth rate of non-starter adjunct cultures, thus preventing the over-acidification that may occur during cheese manufacturing. A preliminary screening using four different concentrations $(0.20 \%, 0.30 \%, 0.50 \%$, and $0.70 \%)$ of A. platensis extract and four starter and three non-starter lactic acid bacteria strains was performed by impedometric analysis. This allowed us to select one starter and one non-starter strain to be used in the in vitro simulation of a co-culture in milk with the best antimicrobial concentration $(0.3 \%)$. The growth dynamics of the two selected strains, starter Lactococcus lactis 1426 and non-sarter Lacticaseibacillus rhamnosus 1473, co-cultured for $120 \mathrm{~h}$ was monitored by three different approaches: (i) plate counting on M17, for the enumeration of lactococci, and MRS for lactobacilli; (ii) fluorescence microscopic counting of viable and non-viable coccoid Lactococcus lactis 1426 and rod-shaped Lacticaseibacillus rhamnosus 1473 cells; (iii) the overall estimation of co-culture growth behavior by impedometric parameters Lag, Rate, and yEnd. All the data obtained from the in vitro simulation were in agreement, revealing that a slowdown of non-starter growth occurred, while the starter strain was not affected, or slightly stimulated, from the antimicrobial presence. In particular, the growth of Lb. rhamnosus 1473 was delayed without adversely compromise the cells' integrity, connected with metabolic functions, showing a great potential for use in cheese production.
\end{abstract}

Keywords: spirulina extract; attenuated cultures for cheese production; impedance microbiology; fluorescence microscopy; co-culturing; lactic acid bacteria; Lacticaseibacillus; NSLAB

\section{Introduction}

Non starter lactic acid bacteria (NSLAB), mainly belonging to the Lacticaseibacillus genus [1], predominate during the ripening of several cheese varieties and are known to be responsible for the development of appreciated organoleptic characteristics, as well as, in some cases, of defects [2]. As an example, the presence of adventitious NSLAB from milk in raw milk cheeses could introduce a variable in the ripening process that cannot be easily controlled, bringing about possible fluctuations in the characteristics of the final product $[3,4]$. This variability could be minimized by adding selected adjunct cultures and controlling their development. To this aim, as well as to enhance the flavor and sensorial characteristics of ripened cheeses, the use of non-starter as adjunct cultures has gained increasing attention during the last few years [2]. This kind of culture has also been used to enhance the sensorial characteristics of pasteurized or sterilized milk cheeses or the flavour of low-fat cheeses [5,6]. Unfortunately, the main drawback in the use of these cultures is the possible over-acidification due to their rapid growth, particularly during curd acidification, which could lead to changes in both the texture and sensory characteristics of the cheeses [5-7]. In fact, the production of an excess of lactic acid might negatively influence the final cheese flavour and texture [5]. To avoid this, a strategy developed throughout the years is the use of non-starter adjunct strains in form of attenuated cultures. These 
are $\mathrm{LAB}$ that do not have the capacity to grow and produce lactic acid during the first stages of cheese making and thus do not compete with the activity of the main starter. On the contrary, they accelerate and improve flavour and texture development during cheese ripening without affecting the characteristics of cheese by lowering the $\mathrm{pH}$ and changing the rheology of the product. To date, several methods have been used to achieve cultures attenuation, including heat treatment, freezing and thawing, freeze or spray-drying, lysozyme addition, the use of solvents, and high-pressure treatment [7]. More recently, sonication has also been proposed for the attenuation of adjuncts cultures of mesophilic NSLAB used in Italian Caciotta-type cheese making [5]. The desired result of using such above-mentioned methods is the achievement of a certain degree of cell lysis with the consequent release of intracellular enzymes in the matrix [8,9]. It is known that bacterial intracellular enzymes can be responsible for the important transformation of different milk components that lead to the formation of peculiar aroma during cheese ripening [10]. However, the attenuation of adjunct cultures should avoid adversely compromising their viability and functional metabolisms [11]. In this frame, a step forward in the obtainment of attenuated non-starter adjunct cultures could be the use of a non-invasive method to slow the cell growth rate while avoiding their disruption. To this aim, we propose the use of specific concentrations of Arthrospira platensis, commonly known as spirulina, extract. The antimicrobial activity of this extract has been previously studied against food pathogenic and food alterative bacteria, proving its high efficacy $[12,13]$. In the present study, the ability of different concentrations of $A$. platensis extract to modulate the growth of starter (SLAB) and NSLAB lactic acid bacteria was studied. By means of impedometric analysis and the fluorescent microscopic evaluation of cells' viability, it was possible to observe the impact of $A$. platensis extract on the studied strains, suggesting the most suitable balance among SLAB, NSLAB, and A. platensis extract for possible application in cheesemaking.

\section{Materials and Methods}

\subsection{Arthrospira Platensis Extraction Process}

The A. platensis powder used in the present study was kindly provided by S.a.Ba.r. (Novellara, Emilia-Romagna Region, Italy). The extraction process was performed foowing the protocol aready described by Martelli et al. (2020) [14].

After a double extraction followed by filtration $(11 \mu \mathrm{m}$ filter papers, $150 \mathrm{~mm} \varnothing$, Whatman, Schleicher \& Schuell, Maidstone, GB), the extract was dried and then supended in sterile water before being stored at $-80{ }^{\circ} \mathrm{C}$ until use.

\subsection{Bacterial Strains and Culture Conditions}

Four strains commonly used as starters in milk fermentation, such as Streptococcus thermophilus (2) and Lactococcus lactis (2), and three non starter strains Lacticaseibacillus casei, Lacticaseibacillus paracasei, and Lacticaseibacillus rhamnosus,belonging to the formerly known Lactobacillus casei group [1] were chosen for the study (Table 1).

Table 1. Strains, origin and growth conditions.

\begin{tabular}{ccccc}
\hline Species & Strain & Origin & Growth Conditions & Reference Paper \\
\hline Streptococcus thermophilus & 526 & Milk & M17, $42^{\circ} \mathrm{C}$ anaerobiosis & {$[15]$} \\
Streptococcus thermophilus & 4028 & Curd & M17, $42^{\circ} \mathrm{C}$ anaerobiosis & {$[15]$} \\
Lactococcus lactis & 4064 & Cheese & M17, $30^{\circ} \mathrm{C}$ anaerobiosis & {$[15]$} \\
Lactococcus lactis & 1426 & Milk & M17, $30^{\circ} \mathrm{C}$ anaerobiosis & {$[15]$} \\
Lacticaseibacillus casei & 2046 & Cheese & MRS, $37^{\circ}$ C anaerobiosis & {$[16]$} \\
Lacticaseibacillus paracasei & 2333 & Cheese & MRS, $37^{\circ} \mathrm{C}$ anaerobiosis & {$[16]$} \\
Lacticaseibacillus rhamnosus & 1473 & Cheese & MRS, $37^{\circ}$ C anaerobiosis & {$[16]$} \\
\hline
\end{tabular}

The strains belonging to the collection of the Food Microbiology group of the Food and Drug Department (University of Parma, Italy), were previously isolated from different food matrixes and identified by $16 \mathrm{~S}$ rRNA sequencing (Table 1). 
The strains, were maintained as frozen stock cultures at $-80{ }^{\circ} \mathrm{C}$ in $\mathrm{M} 17$ (Oxoid, Ltd., Basingstoke, United Kingdom) broth for Lactococcus spp. and MRS (Oxoid, Ltd., Basingstoke, United Kingdom) broth for Lactobacillus spp, containing 20\% (v/v) glycerol. The strains were revitalized in the appropriate medium by two overnight sub-culturing $2 \%$ $(v / v)$ at $37{ }^{\circ} \mathrm{C}$ for Lacticaseibacillus strains, $30{ }^{\circ} \mathrm{C}$ for L. lactis, and $42{ }^{\circ} \mathrm{C}$ for S. thermophilus (Table 1).

\subsection{Experimental Design}

The experimental design was divided into two main parts. At first, all the strains (Table 1), after revitalization, were tested for their ability to grow in milk with and without the addition of four different concentrations $(0.20,0.30,0.50$, and $0.70 \%)$ of A. platensis extract (Figure 1a). This step was crucial for the second part of the experiment, which consisted of the selection of two strains, one starter (SLAB) and one non-starter (NSLAB), to be used for the in vitro simulation of a co-culture. The fermentation was carried out for $120 \mathrm{~h}$, performing culture dependent and independent analyses at each samping time (Figure 1b).

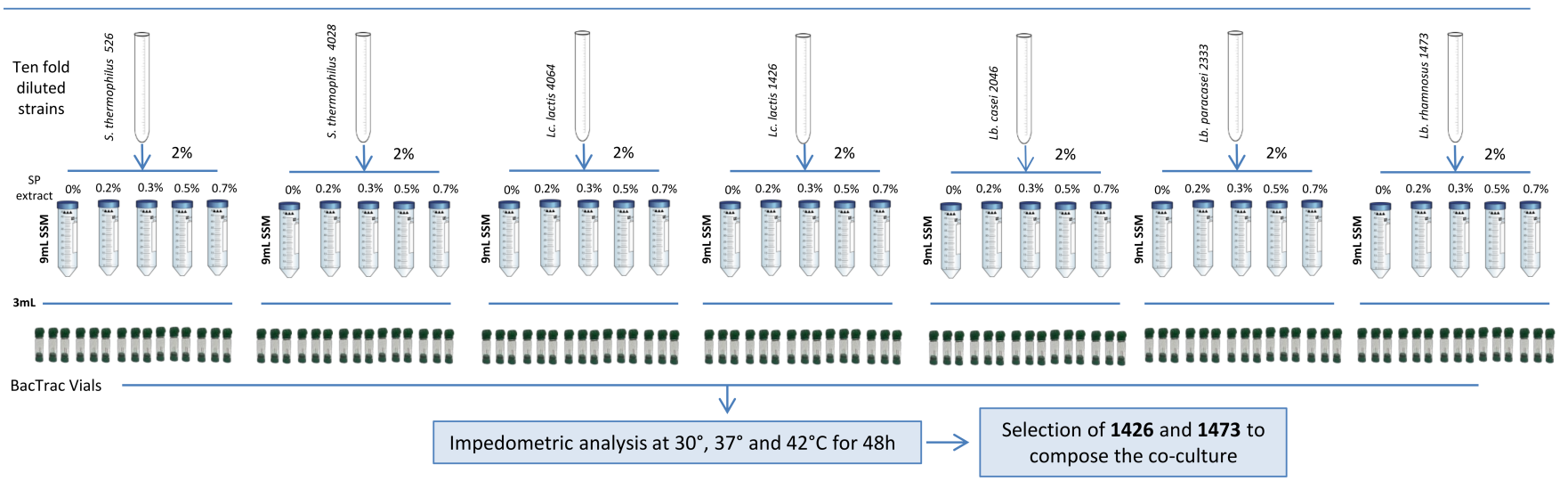

$2^{\text {nd }}$ STEP: in vitro simulation of co-culture

co-culture 1: Starter 1426 and non-starter 1473 mixed in ratio 1:1

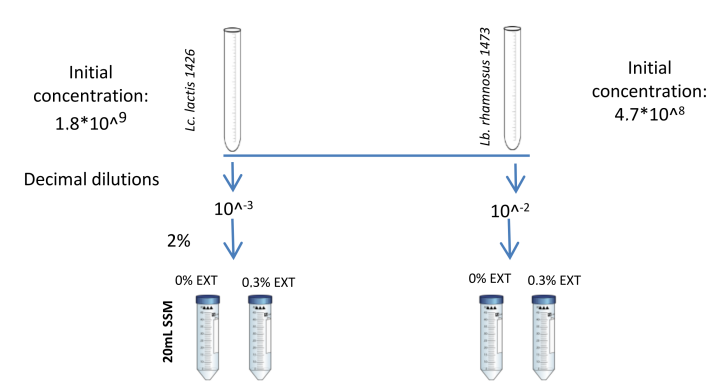

BacTrac

analysis

at $30^{\circ} \mathrm{C}$

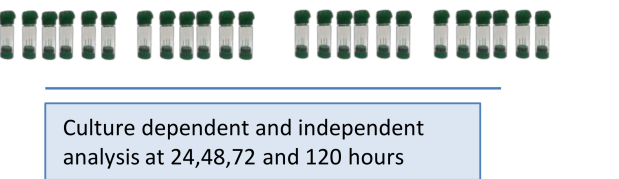

co-culture 2: Starter 1426 and non-starter 1473 mixed in ratio 1000:1

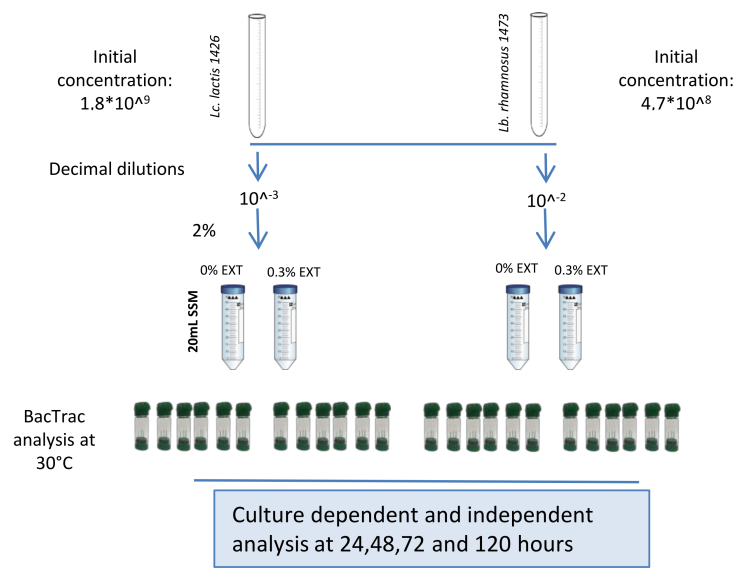

Figure 1. Experimental design. In the figure (a) the scheme of the strain selection precudure is reported, and (b) the schematic representation of the in vitro simulation of co-culture is reported. 


\subsection{Single Strain Growth Condition and Analysis}

After two sub-culturing step in MRS and M17 (Table 1), the strains were sub-cultured twice and incubated overnight at their optimum temperature, as reported in (Table 1), in $(2 \% v / v)$ skim milk powder (SSM) (Oxoid Ltd.). SSM was reconstituted to $10 \%(w / v)$ and pasteurized in an autoclave at $90{ }^{\circ} \mathrm{C}$ for $10 \mathrm{~min}$ before use. A. platensis extract was added to the SSM to reach final concentrations $(v / v)$ of (a) $0.20 \%$, (b) $0.30 \%$, (c) $0.50 \%$, d) $0.70 \%$. A negative control sample without any addition of extract was also considered as e) $0 \%$ (Figure 1). After the last sub-culturing step in SSM, each bacterial culture was ten-fold diluted in Ringer's solution (Oxoid) and used to inoculate $2 \%(v / v) 9 \mathrm{~mL}$ of SSM supplemented, respectively and separately, with all the different concentrations of $A$. platensis extract (Figure 1). A total of $3 \mathrm{~mL}$ of inoculated SSM was transferred into sterilized BacTrac $4300^{\circledR}$ vials (SY-LAB, Neupurkersdorf, Austria), and incubated at the optimal growth temperature of each strain (Table 1). All the analyses were carried out in triplicate and monitored for $24 \mathrm{~h}$ by measuring the impedometric signal every $10 \mathrm{~min}$ by the BacTrac $4300{ }^{\circledR}$ Microbiological Analyzer (SY-LAB, Neupurkersdorf, Austria).

\subsection{In Vitro Simulation of Selected SLAB and NSLAB}

The starter strain L. lactis 1426 and the non-starter strain $L b$. rhamnosus 1473 were selected and used to prepare the co-culture of (1) L. lactis 1426 and Lb. rhamnosus 1473, added to SSM in a ratio of 1:1, and the co-culture of (2) L. lactis 1426 and Lb. rhamnosus 1473 , added to SSM in a ratio of 1000:1. The initial concentration of the two strains was estimated by plate count as $4.7 \times 10^{8}$ for Lb. rhamnosus 1473 and $1.8 \times 10^{9}$ for L. lactis 1426. These were differently diluted to reach the same inoculum level to be added in SSM (Figure 1b). Both co-cultures 1 and 2 were inoculated in SSM without antimicrobial addition ( $0 \%$, named Control (C), and with the addition of $0.3 \%$ of antimicrobial (A), and then analysed continuously for $120 \mathrm{~h}$ at $30{ }^{\circ} \mathrm{C}$ by a BacTrac $4300^{\circledR}$ Microbiological Analyzer system. After 24, 48, 72, and $120 \mathrm{~h}$ of incubation, samples were taken from the vials for the $\mathrm{pH}$ measurement and culture dependent (viable count) and independent (Fluorescence microscopy) analyses (Figure 1b).

\subsection{Impedometric Measurement}

Impedance analyses were performed for single strains and co-cultures by means of the BacTrac $4300^{\circledR}$ Microbiological Analyzer system. The M\% values were measured and recorded every $10 \mathrm{~min}$ for $48 \mathrm{~h}[15,17]$. Each experiment was replicated twice and each analytical variable was measured in triplicate. The results of the impedometric analysis were analyzed, as previously reported by Bancalari et al. (2016) [15].

\section{7. $\mathrm{pH}$ Measurement}

After $24,48,72$, and $120 \mathrm{~h}$ of incubation $\mathrm{pH}$ was measured by means of a $\mathrm{pH}$ meter (Beckman Instrument mod $\Phi 350$, Furlenton, CA, USA) and a glass electrode (Hamilton, Bonaduz, Switzerland).

\subsection{Culture-Dependent Viable Counts of the Co-Cultures}

After 24, 48, 72, and $120 \mathrm{~h}$ of incubation of the two co-cultures (Figure 1), aliquots of the fermented SSMs were aseptically taken, decimally diluted in Ringer's solution, inoculated in MRS and M17, and respectively incubated at $37^{\circ} \mathrm{C}$ and $30^{\circ} \mathrm{C}$. The acidified MRS agar (aMRS) was prepared according to the manufacturer's instructions, acidified to 5.4 with glacial acetic acid (Merck, Darmstadt, Germany), and then autoclaved at $121{ }^{\circ} \mathrm{C}$ for $20 \mathrm{~min}$.

\subsection{Culture-Independent Viable Counts of the Co-Cultures}

Fluorescence microscopy count was performed using the LIVE/DEAD ${ }^{\circledR}$ Baclight ${ }^{\mathrm{TM}}$ Bacterial Viability kit (Molecular Probes, OR, USA), as previously reported (18-20). Nikon filter set B2A FITC was used to visualize green-stained cells (SYTO 9) and the Nikon 
filter set G-2E/C to visualize red-stained cells (propidium iodide). Pictures of each field were taken and then superimposed through the Nis Elements software (ver. 2.10 Nikon Instruments Inc., Walt Whitman Road Melville, NY 11747-3064, USA) [18-20]. Cells were counted as previously described [18-20]. A minimum of five separate microscopic fields were counted for each sample. Results were reported as average values \pm the standard deviation of the total, viable, and non-viable cells referred to $1 \mathrm{~mL}$.

\subsection{Statistical Analysis}

To investigate the effect of the different concentrations of antimicrobics on the strains, a two-way analysis of variance (ANOVA) model was performed using SPSS Statistics v. 25 (IBM, Armonk, NY, USA). One-way ANOVA and Tukey's HSD post hoc test were applied to test significant differences $(p<0.05)$.

\section{Results and Discussion}

\subsection{Single Strains Selection}

The impedometric analysis of the single strains cultures was performed by means of BacTrac $4300^{\circledR}$, which enables the measurement of their growth in real time by registering the variation in electrical conductivity in the medium. In fact, during duplication viable bacterial cells break down sugars present in the medium into the smallest molecules, which increase the conductivity of the medium. Therefore, the quantification of this variation had been used as a measure of the microbial metabolism [15] and, in the present study, as a measure of lactic acid fermentation [17]. The instrument is able to simultaneously measure and record, every $10 \mathrm{~min}$, two impedance values for each single measurement: (i) the $M$-value, which corresponds to the change in the overall medium impedance, and (ii) the $E$-value, which is the measure of the impedance variation in the vicinity of the electrodes. Both these values are shown as relative changes compared to a starting value and expressed as $M \%$ and $E \%$ [17]. At the end of the analysis, $M \%$ values were approximated [15] and used to calculate the kinetic parameters useful to describe the effect of $A$. platensis extract on strain growth. Differently from previous research, where the bactericidal and bacteriostatic effects of $A$. platensis extract were evaluated using a Lag parameter as a measure of cells' adaptation time and yEnd as a measure of the maximum acidifying capacity $[13,15]$, in this study the Rate parameter was also considered and used as a measure of the acidification rate. The greater the Rate value, the faster the acidification speed of the strain (Table 2). In Table 2, three kinetic parameters are reported for each considered strain and concentration of $A$. platensis extract. Usually, SLAB used for cheese-making are required to rapidly convert lactose into lactic acid, with the consequent fast acidification of the curd [21,22]. Thus, regarding growth parameters, a SLAB strain is expected to have a short Lag phase, a high acidification Rate, and also a good acidifying capacity, showing a high value of yEnd [15]. Both for S. thermophilus strains 526 and 4028, the Lag and Rate values in SSM with $0.20 \%$ of A. platensis extract did not significantly differ from the control ( $0 \%$ ) (Table 2$)$. By increasing the $A$. platensis extract concentration in SSM, a significant increase in the Lag parameter was observed. On the other hand, the Rate and yEnd values showed a significant decrease, until any growth was detected for S. thermophilus 526 in the presence of $0.50 \%$ and $0.70 \%$ and $S$. thermophilus 4028 in the presence of $0.70 \%$ of $A$. platensis extract (Table 2). These results mean that the increasing concentration of antimicrobial in SSM led to a delay in the growth of both the strains, together with a negative effect on their growth speed and acidifying capacity. Regarding the two other strains belonging to the SLAB species, L. lactis 1426 and L. lactis 4064, an interesting trend in the growth was found. In fact, the Lag values of both strains grown in the presence of $0.20 \%$ and $0.30 \%$ of extract were statistically lower or equal compared to the Lag values recorded for the control $(0 \%)$ (Table 2). In particular, the strain L. lactis 1426 showed a significant decrease in the Lag values in the presence of $0.30 \%$ of the antimicrobial extract. This could be ascribed to the strain-specific ability to metabolize some components present in the A. platensis extract, such as small peptides or monosaccharides derived from the breakdown of extracellular polysaccharides [23]. 
This trend was observed only for the Lag values, while other considered parameters, Rate and yEnd, were gradually decreased by increasing the concentration of antimicrobial in the SSM (Table 2). On the other hand, NSLAB are expected to show a slow growth as well as low acidification Rate and scarce acidifying capacity, as their role has to be played after the acidification, in particular during ripening $[3,24,25]$. Based on this, NSLAB are supposed to have a long Lag time, with small values for Rate and yEnd. In the present study, despite belonging to a species classified as NSLAB [21], Lb. casei 2046 showed behavior that was comparable to that of the SLAB species. Indeed, it had a short Lag phase and a good acidification capacity when grown in SSM with $0.20 \%$ of A. platensis extract. As observed for SLAB, increasing concentrations of the extract had higher impacts on the growth parameters (Table 2). The other NSLAB strains, Lb. rhamnosus 1473 and Lb. paracasei 2333 , showed different responses to the A. platensis extract as compared to $L b$. casei 2046. Actually, they had a statistically longer Lag phase as compared to the control at each antimicrobial concentration considered. Furthermore, increasing concentrations of the extract in SSM also affected the acidification capacity of both the strains, as can be observed in the decreasing yEnd recorded values (Table 2). For a better view of the effect of A. platensis extract on the strains' growth, a graphical representation of the $\Delta$ value of each parameter, calculated as the difference with respect to the control value $(0 \%)$, was reported (Figure 2$)$. For all the parameters ( $\Delta \mathrm{Lag}, \Delta$ Rate, and $\Delta$ yend), the tallest histogram bars, the highest increase or decrease in the values were observed (Figure 2a). Taken together, the data show that the A. platensis extract concentration of $0.30 \%$ did not interfere with the starter activity. On the other hand, it was responsible for the delay in the NSLAB growth (Figure 2). For this reason, this concentration was chosen to be tested in the next experimental step. As the SLAB strain L. lactis 1426 was stimulated by the presence of this amount of $A$. platensis extract in SSM with a decrease in $\Delta$ Lag of $1.92 \mathrm{~h}$ (Figure 2), it was considered as the most suitable candidate to be used as a starter in the in vitro simulation of co-culturing. In the same way, the NSLAB strain Lb. rhamnosus 1473 showed a good increase in the Lag phase as compared to the control and a good reduction in the acidifying Rate and capacity when grown in SSM with $0.30 \%$ of A. platensis extract, thus it was chosen to be used as NSLAB in the in vitro simulation of co-culturing. This choice was corroborated by the fact that the lactobacilli isolated by quality cheeses, as in the case of $L b$. rhamnosus 1473, showed a positive effect on cheese quality during ripening [11].

\subsection{In Vitro Simulation of SLAB L. lactis 1426 and NSLAB Lb. rhamnosus 1473 Co-Culturing}

Two co-coltures were prepared with the chosen strains. Co-culture 1 was obtained by mixing L. lactis 1426 and Lb. rhamnosus 1473 in SSM in a ratio of 1:1, while co-culture 2 was obtained by mixing L. lactis 1426 and Lb. rhamnosus 1473 in SSM in a ratio of 1000:1 to simulate the proportion commonly used in cheese making processes [26]. The growth dynamics of the two strains co-cultured for $120 \mathrm{~h}$ were monitored by three different approaches: (i) plate counting on M17 for the enumeration of lactococci and MRS for lactobacilli; (ii) the fluorescent microscopic counting of viable (green) and non-viable (red) coccoid cells of L. lactis 1426 and rod-shaped cells of Lb. rhamnosus 1473; (iii) the overall estimation of co-culture growth behavior by impedometric parameters Lag, Rate, and yEnd. The initial concentrations of the strains in each co-culture were confirmed by plate count, as reported in (Figure 3a,b).

The growth of the starter strain L. lactis 1426 was not affected by the presence of $A$. platensis extract in either the co-cultures showing a very similar trend to the control. Only after $48 \mathrm{~h}$ of fermentation was a progression of natural cells mortality observed for the starter strain L. lactis 1426 in both the co-cultures (Figure 3a,b). Conversely, the NSLAB strain $L b$. rhamnosus $1473 \mathrm{kept}$ growing during the $120 \mathrm{~h}$ of incubation while showing a significant slowest growth and a lowest cell concentration between 24 and $72 \mathrm{~h}$ (Figure 3a,b) in the presence of the A. platensis extract. These results were confirmed by fluorescence microscopy, which allowed us to count both live and dead cells (Figure 3c,d for co-culture 1 and 2, respectively). However, it has to be noted that cell concentrations under 4 Log 
cells $/ \mathrm{mL}$ were not detected (nd) with this method; thus, the level of viable and dead cells in (Figure 3c,d) under this level could be due to the detection limit. At first, the behavior of the single strains composing the two co-cultures was evaluated. The number of live cells of L. lactis 1426 in co-culture 1 was always significantly higher, up to $1 \mathrm{Log}$, in the control than in the presence of the antimicrobial extract (Figure 3c). These differences can be clearly observed at each sampling point of (Figure 4a) co-cult1_C, where the green coccoid cells were always predominant. Conversely, in the presence of A. platensis extract, the number of dead cells increased progressively, up to approximately $9 \mathrm{Log}$ cells $/ \mathrm{mL}$ at $120 \mathrm{~h}$ (Figure 3b and red coccoid cells in Figure 4a co-cult1_A). This could be attributable to the antimicrobial effect of the extract on the cells. In particular, the effect could be ascribed to the presence of $\gamma$-linoleic acid, 1-acetodecane, and especially high lipid concentrations, typical of spirulina extract, which could have compromised the integrity of the cellular membrane [27]. Although the initial concentration of the inoculated cells was the same in both the co-cultures, the behavior observed for the starter strain L. lactis 1426 in co-culture 2 was different. In fact, the number of live cells was constantly lower in the presence of A. platensis extract until $72 \mathrm{~h}$ of incubation, when the maximum amount of live cells was detected in both the conditions. After that, the live cell count decreased down to the minimum value at $120 \mathrm{~h}$ (Figures $3 \mathrm{~d}$ and $4 \mathrm{~b}$, co-cult2_C and co-cult2_A). In parallel, the dead L. lactis 1426 cells count was always higher in the presence of the antimicrobial, until the end of fermentation (120 h) (Figure 3d and red coccoid cells in Figure 4b, co-cult2_C and co-cult2_A).

Table 2. Lag, Rate, and yEnd parameters of the seven considered strains grown in skimmed milk (SSM) with different $A$. platensis extract concentrations.

\begin{tabular}{|c|c|c|c|c|c|c|}
\hline \multirow[b]{2}{*}{ Strains } & & \multicolumn{5}{|c|}{ A. platensis Extract Concentration } \\
\hline & & $0 \%$ & $0.20 \%$ & $0.30 \%$ & $0.50 \%$ & $0.70 \%$ \\
\hline \multirow{3}{*}{ S. thermophilus 526} & Lag & $1.03^{\mathrm{b}} \pm 0.01$ & $1.39^{b} \pm 0.08$ & $1.91^{\mathrm{a}} \pm 0.21$ & $\mathrm{nd}^{\mathrm{c}} \pm 0.11$ & $\mathrm{nd}^{\mathrm{c}} \pm 0.18$ \\
\hline & Rate & $5.40^{\mathrm{a}} \pm 0.15$ & $5.30^{\mathrm{a}} \pm 0.28$ & $3.77^{\mathrm{b}} \pm 0.01$ & $\mathrm{nd}^{\mathrm{c}} \pm 0.01$ & $\mathrm{nd}^{\mathrm{c}} \pm 0.01$ \\
\hline & yEnd & $29.35^{a} \pm 0.18$ & $23.29^{b} \pm 0.08$ & $20.59^{c} \pm 0.20$ & nd $^{\mathrm{d}} \pm 0.16$ & $\mathrm{nd}^{\mathrm{d}} \pm 0.01$ \\
\hline \multirow{3}{*}{ S. thermophilus 4028} & Lag & $<1^{\mathrm{c}} \pm 0.09$ & $1.41^{\mathrm{c}} \pm 0.14$ & $2.37^{\mathrm{b}} \pm 0.19$ & $10.84^{\mathrm{a}} \pm 0.01$ & $\mathrm{nd}^{\mathrm{d}} \pm 0.01$ \\
\hline & Rate & $4.06^{\mathrm{a}} \pm 0.28$ & $3.98^{\mathrm{a}} \pm 0.18$ & $2.2^{b} \pm 0.01$ & $0.29^{c} \pm 0.15$ & $\mathrm{nd}^{\mathrm{c}} \pm 0.01$ \\
\hline & yEnd & $29.27^{\mathrm{a}} \pm 0.11$ & $21.20^{\mathrm{b}} \pm 0.01$ & $13.79^{c} \pm 0.08$ & $4.97^{\mathrm{d}} \pm 0.07$ & $\mathrm{nd}^{\mathrm{e}} \pm 0.01$ \\
\hline \multirow{3}{*}{ L. lactis 1426} & Lag & $4.95^{b} \pm 0.01$ & $3.42^{c} \pm 0.22$ & $3.01^{c} \pm 0.28$ & $6.24 \mathrm{a} \pm 0.12$ & $32.93^{d} \pm 0.08$ \\
\hline & Rate & $5.79^{\mathrm{a}} \pm 0.08$ & $2.97^{b} \pm 0.01$ & $1.95^{\mathrm{c}} \pm 0.01$ & $0.64^{\mathrm{d}} \pm 0.01$ & $0.09^{\mathrm{e}} \pm 0.01$ \\
\hline & yEnd & $27.39^{a} \pm 0.21$ & $19.90^{b} \pm 0.12$ & $18.18^{c} \pm 0.15$ & $10.23^{\mathrm{d}} \pm 0.01$ & $3.06^{\mathrm{e}} \pm 0.28$ \\
\hline \multirow{3}{*}{ L. lactis 4064} & Lag & $3.95^{b} \pm 0.01$ & $2.74^{c} \pm 0.08$ & $3.87^{b} \pm 0.08$ & $6.07^{a} \pm 0.01$ & $\mathrm{nd}^{\mathrm{d}} \pm 0.01$ \\
\hline & Rate & $6.11^{a} \pm 0.28$ & $2.15^{b} \pm 0.01$ & $1.41^{\mathrm{c}} \pm 0.01$ & $0.39^{d} \pm 0.25$ & $\mathrm{nd}^{\mathrm{e}} \pm 0.08$ \\
\hline & yEnd & $27.05^{a} \pm 0.15$ & $17.17^{b} \pm 0.02$ & $13.80^{c} \pm 0.28$ & $8.6^{\mathrm{d}} \pm 0.21$ & $\mathrm{nd}^{\mathrm{e}} \pm 0.01$ \\
\hline \multirow{3}{*}{ Lb. casei 2046} & Lag & $1.28^{b} \pm 0.26$ & $1.41^{\mathrm{b}} \pm 0.01$ & $2.37^{\mathrm{c}} \pm 0.06$ & $10.84^{\mathrm{a}} \pm 0.01$ & $\mathrm{nd}^{\mathrm{d}} \pm 0.08$ \\
\hline & Rate & $1.04^{c} \pm 0.01$ & $3.98^{a} \pm 0.08$ & $2.21^{\mathrm{b}} \pm 0.01$ & $0.29^{\mathrm{d}} \pm 0.15$ & $\mathrm{nd}^{\mathrm{e}} \pm 0.01$ \\
\hline & yEnd & $29.52^{a} \pm 0.13$ & $21.20^{b} \pm 0.11$ & $13.79^{c} \pm 0.07$ & $4.97^{\mathrm{d}} \pm 0.08$ & $\mathrm{nd}^{\mathrm{e}} \pm 0.01$ \\
\hline \multirow{3}{*}{ Lb. rhamnosus 1473} & Lag & $8.43^{e} \pm 0.15$ & $12.72^{\mathrm{d}} \pm 0.01$ & $13.55^{c} \pm 0.06$ & $16.94^{b} \pm 0.01$ & $28.25^{\mathrm{a}} \pm 0.01$ \\
\hline & Rate & $1.19^{\mathrm{a}} \pm 0.21$ & $1.40^{\mathrm{a}} \pm 0.1$ & $0.96^{\mathrm{b}} \pm 0.11$ & $0.70^{c} \pm 0.15$ & $0.22^{\mathrm{d}} \pm 0.12$ \\
\hline & yEnd & $22.01^{\mathrm{a}} \pm 0.08$ & $19.81^{b} \pm 0.01$ & $14.96^{\mathrm{c}} \pm 0.14$ & $9.49^{\mathrm{d}} \pm 0.01$ & $3.02^{\mathrm{e}} \pm 0.01$ \\
\hline \multirow{3}{*}{ Lb. paracasei 2333} & Lag & $10.32^{\mathrm{e}} \pm 0.08$ & $11.71^{\mathrm{d}} \pm 0.02$ & $14.73^{c} \pm 0.01$ & $18.74^{b} \pm 0.13$ & $31.67^{a} \pm 0.01$ \\
\hline & Rate & $0.69^{b} \pm 0.01$ & $0.84^{\mathrm{a}} \pm 0.01$ & $0.71^{b} \pm 0.15$ & $0.47^{c} \pm 0.12$ & $0.15^{\mathrm{d}} \pm 0.28$ \\
\hline & yEnd & $19.69^{a} \pm 0.21$ & $16.89^{b} \pm 0.11$ & $15.24^{\mathrm{c}} \pm 0.03$ & $10.69^{d} \pm 0.01$ & $3.60^{\mathrm{e}} \pm 0.01$ \\
\hline
\end{tabular}

Lag is reported in hours; nd: not detected within $48 \mathrm{~h}$. Values are the mean \pm SD of at least two separate experiments in which each variable was measured in triplicate. Different superscript lowercase letters a-e within the same row highlight significant differences according to ANOVA $(p<0.05)$ among each parameter at different $A$. platensis concentrations. 


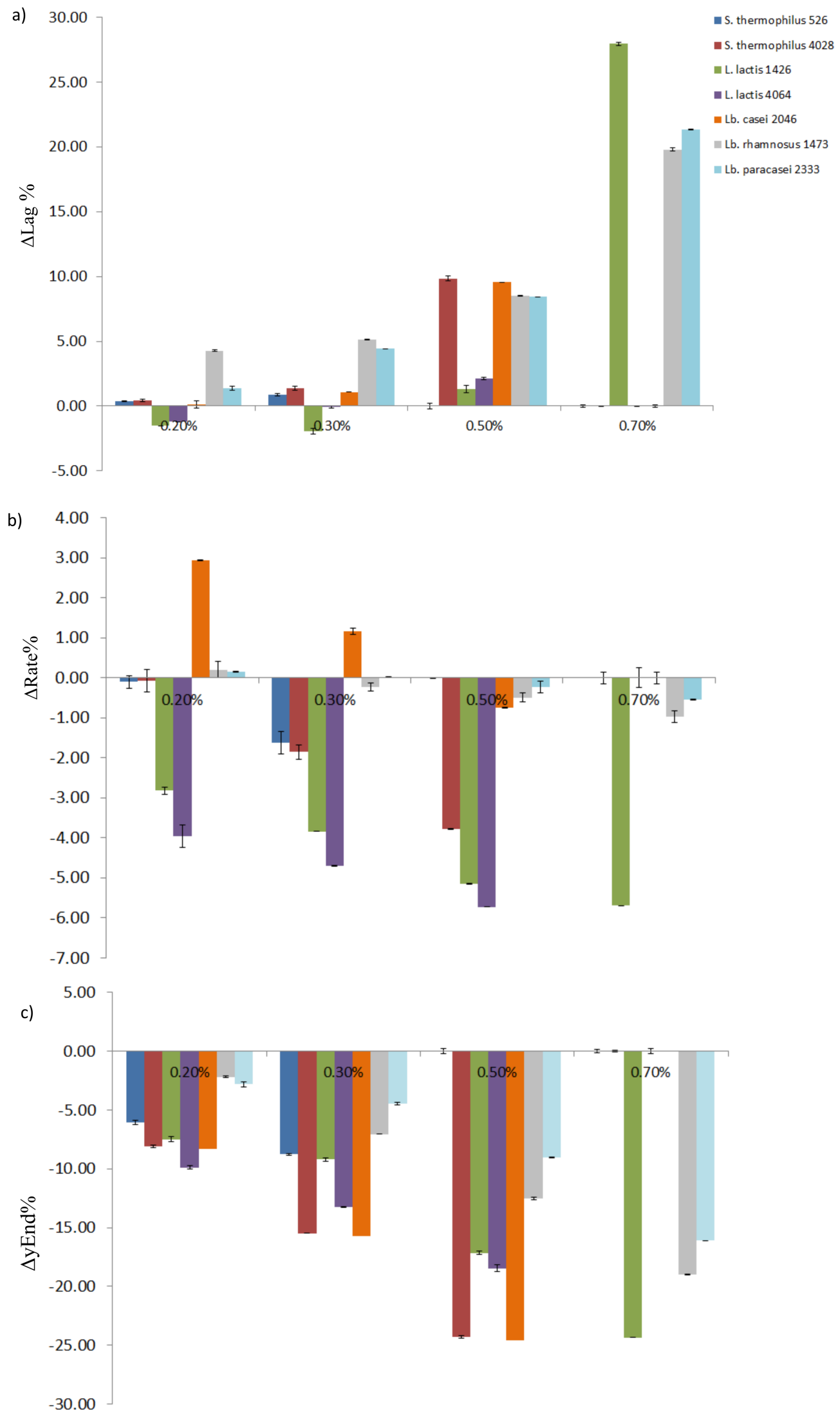

Figure 2. Graphical representation of the $\Delta$ values of each parameter calculated as the difference from the control value $0 \%$. In the figure: (a) $\Delta \mathrm{Lag}$; (b) $\Delta$ Rate; (c) $\Delta y$ End. On the X-axis, the spirulina extract concentrations are reported: $0.20 \%, 0.30 \%, 0.50 \%$, and $0.70 \%$. 

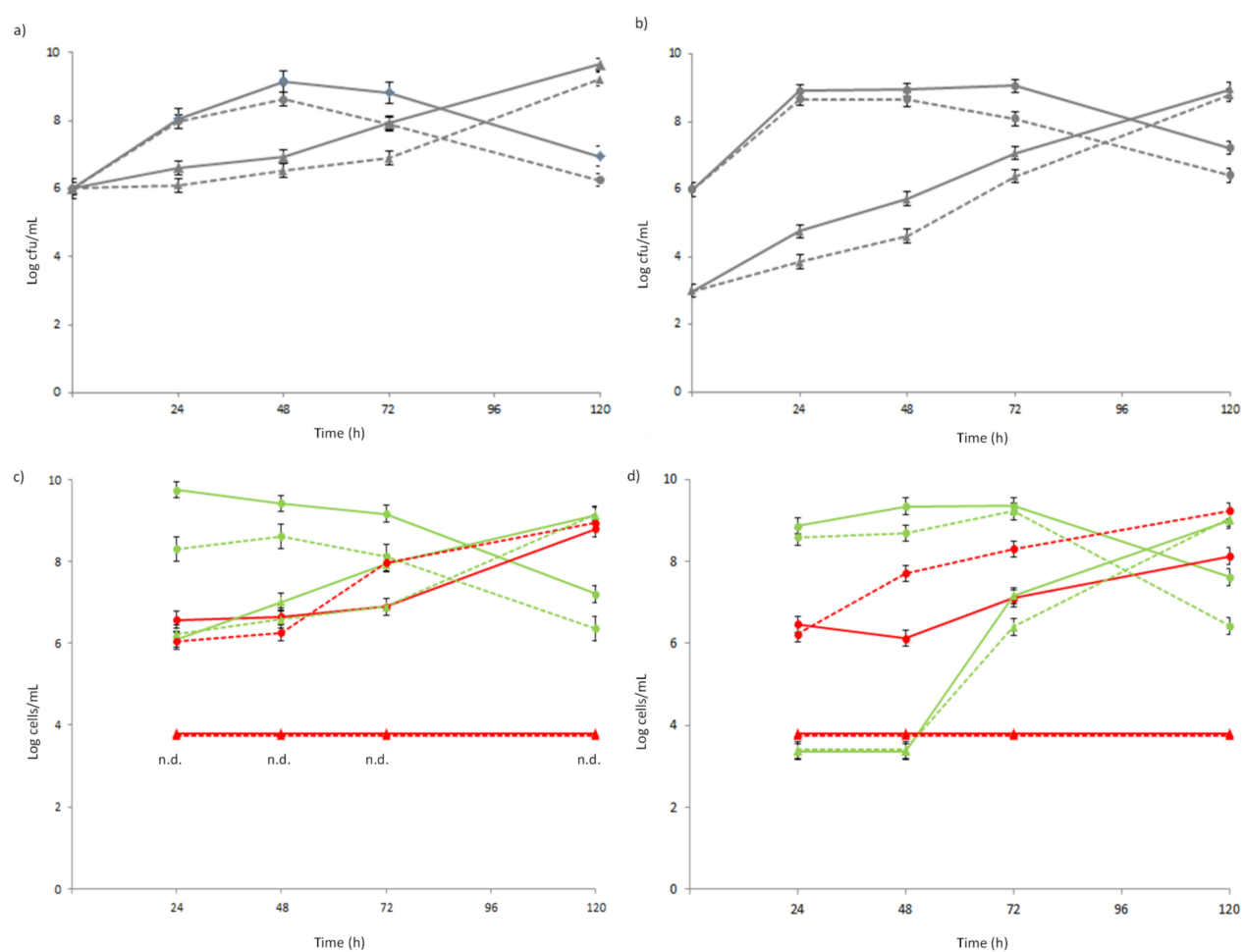

Figure 3. Enumeration of L. lactis $1426(\bullet)$ and Lb. rhamnosus $1473(\mathbf{\Delta})$ cultivated in co-culture for $120 \mathrm{~h}$ in the presence (dotted lines) and absence (solid line) of $0.30 \%$ A. platensis extract. Plate counts of co-culture 1 (a) and co-culture 2 (b). Fluorescent microscopic counts of co-culture 1 (c) and co-culture 2 (d): the number of viable cellsare in green and in red are the number of dead cells (n.d.: not detected; the cells' concentration was under the 3 Log cells $/ \mathrm{mL}$ ).

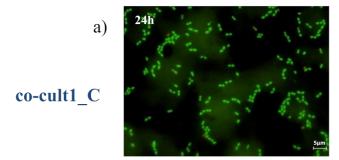

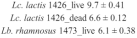

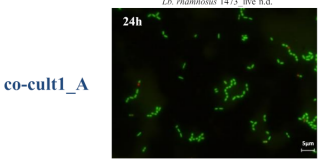

b)

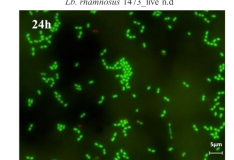

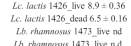

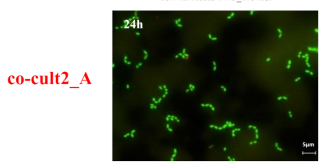

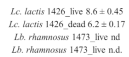
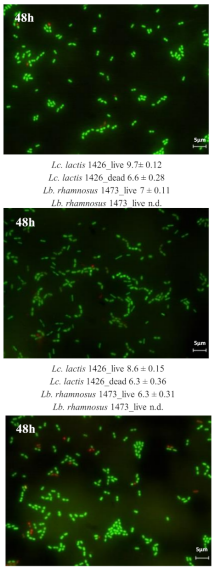

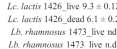

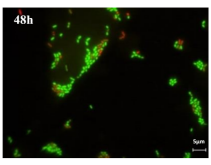

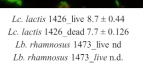
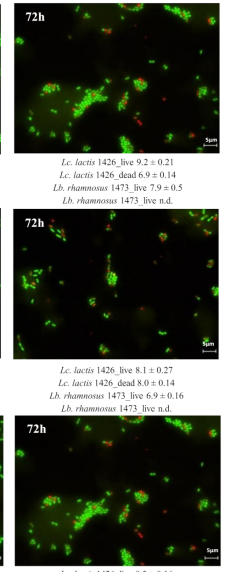

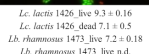

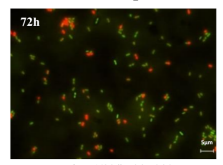

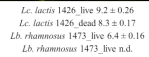
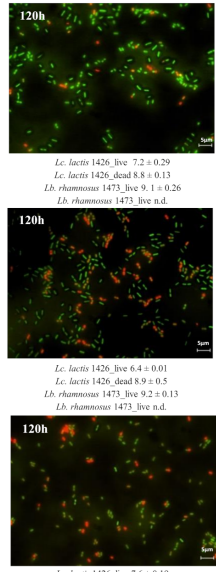

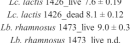

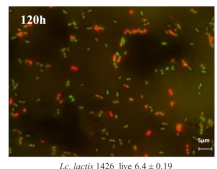

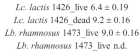

Figure 4. Fluorescence microscopy images of co-culture 1 (a) and co-culture 2 (b), with (co-Cult_A) and without (co-cult_C) $0.3 \%$ of antimicrobial A. platensis extract at four sampling time points: 24,48 , 72 , and $120 \mathrm{~h}$ of incubation. Live cells labelled with Syto 9 appear in green, and dead cells labelled with propidium iodide (PI) appear in red. Scale bars are $5 \mu \mathrm{m}$ in length. The Starter strain cells Lc. 1426 are round-shaped, while the non starter strain cells Lb. 1473 are rod-shaped. 
Concerning the NSLAB strain Lb. rhamnosus 1473 , the number of live cells in co-culture $1 \mathrm{was}$ similar at the beginning of fermentation and after 24 and $120 \mathrm{~h}$ of incubation, while it showed a slower growth in the presence of antimicrobial extract between 24 and $48 \mathrm{~h}$ (Figure 3c and green rod-shaped cells in Figure 4a co-cult1_C and co-cult1_A). Differently, the number of live $L b$. rhamnosus 1473 cells in co-culture 2 was under the limit of detection for the first $48 \mathrm{~h}$, as expected. In both co-culture 1 and 2 (Figure 3c,d) the number of dead $L b$. rhamnosus 1473 cells was always under the limit of detection. Despite different initial cell concentrations, in both the co-cultures the presence of A. platensis extract slowed down the growth of NSLAB compared to the control (Figure 3d; Figure 4b co-cult2_C and co-cult2_A green rod-shaped cells).

This means that the adjunct culture needed more time to reach the maximum live cell concentration. This has two important effects: (i) given that the cells need more time to grow, they might not interfere with the SLAB activity in the first hours of fermentation, thus avoiding one of the main drawbacks of using secondary adjunt cultures; (ii) the cells could stay alive in the fermented product for a longer period. This is also in good agreement with the already-observed effect of Spirulina in preserving the viability of some probiotic cultures [28].

The overall behavior of the two strains, observed by means of Bactrac $4300^{\circledR}$ in both co-cultures, showed significantly lower values for all the impedometric parameters in the presence of the antimicrobial (Table 3). In particular, for the strain L. lactis 1426, lower Lag values were observed in the presence of $A$. platensis extract. This interesting stimulatory effect, observed only for this strain, could be ascribable to the presence of carbohydrates, free AA, and proteins deriving from the extraction process [29], or to the presence of polysaccharides from spirulina cell breakdown, whose boosting effect on LAB growth has been already reported by Golmakani (et al., 2019) and Martelli (et al., 2020) [28,30,31]. The presence of the extract also affected the Rate values. In fact, in the presence of the antimicrobial, the Rate values were lower, which means a slower cell duplication time. Conversely, the overall acidification capacity was lower in the presence of the antimicrobial, despite an initial stimulatory effect being observed (Table 3).

Table 3. Impedometric parameters describing the growth of the 2 co-cultures with (A) and without antimicrobial A. platensis extract (C).

\begin{tabular}{ccccc}
\hline & Co-Culture1_C & Co-Culture1_A & Co-Culture2_C & Co-Culture2_A \\
\hline Lag & $6.29 \pm 0.02^{\mathrm{a}}$ & $5.79 \pm 0.08^{\mathrm{b}}$ & $6.60 \pm 0.06^{\mathrm{a}}$ & $5.85 \pm 0.03^{\mathrm{b}}$ \\
Rate & $4.94 \pm 0.01^{\mathrm{a}}$ & $1.53 \pm 0.02^{\mathrm{b}}$ & $5.00 \pm 0.05^{\mathrm{a}}$ & $1.16 \pm 0.04^{\mathrm{b}}$ \\
yEnd & $26.71 \pm 0.06^{\mathrm{a}}$ & $15.44 \pm 0.05^{\mathrm{b}}$ & $25.95 \pm 0.08^{\mathrm{a}}$ & $13.78 \pm 0.07^{\mathrm{b}}$
\end{tabular}

Values are the mean \pm SD of at least two separate experiments in which each variable was measured in triplicate Different superscript lowercase letters within the same raw highlight significant differences according to ANOVA $(p<0.05)$ among each parameter.

Concerning the $\mathrm{pH}$ values measured at each sampling point no significative differences were found among the co-cultures, except for both co-culture 1 and 2, which in the presence of the extract showed significantly lower values for $\mathrm{pH}$. This support the results obtained with the impedometric analysis, where a slowing down of the growth and overall acidification capacity was observed.

\section{Conclusions}

The use of A. platensis extract, which, differently from dried Spirulina powder. has neither an unpleasant odor nor color, has been found to have both stimulatory and inhibitory effects on different LAB strains. In particular, we observed a very interesting behavior of one SLAB strain grown in co-culture with a NSLAB strain in the presence of $0.3 \%$ of antimicrobial. The growth of the NSLAB strain Lb. rhamnosus 1473 was slowed down by the antimicrobial's presence, while, on the contrary, the LABSLAB strain L. lactis 1426 was not negatively affected. Furthermore, the growth of the NSLAB strain was delayed without compromising the cells' integrity, meaning that the metabolic potential of these cells is pre- 
served. This can be of great interest for a possible application of attenuated NSLAB in the formulation of adjunct cultures to be employed, for example, in the cheesemaking process.

Despite the fact these results have to be considered as preliminary and further in vivo experiments are needed, it is possible to conclude that the used approach, by means of impedometric analysis, could be successfully applied in the screening of other natural antimicrobials to be used to attenuate the growth of adjunct cultures.

Author Contributions: Conceptualization, E.B. and M.G.; Methodology, E.B., M.G.; Formal Analysis, F.M. and E.B.; Investigation, F.M. and E.B.; Data Curation, E.B. and M.G.; Writing-Original Draft Preparation, E.B. and M.G.; Writing-Review and Editing, E.B., M.G., B.B., and E.N.; Supervision, M.G. All authors have read and agreed to the published version of the manuscript.

Funding: No funding was received.

Institutional Review Board Statement: Not applicable.

Informed Consent Statement: Not applicable.

Data Availability Statement: Not applicable.

Conflicts of Interest: The authors declare no conflict of interest.

\section{References}

1. Zheng, J.; Wittouck, S.; Salvetti, E.; O'Toole, W.; Pot, B.; Vandamme, P.; Walter, J.; Watanabe, K.; Wuyts, S.; Felis, G.E.; et al. A taxonomic note on the genus Lactobacillus: Description of 23 novel genera, emended description of the genus Lactobacillus Beijerinck 1901, and union of Lactobacillaceae and Leuconostocaceae. Int. J. Syst. Evol. Microbiol. 2020, 70, 2782-2858. [CrossRef]

2. Gobbetti, M.; De Angelis, M.; Di Cagno, R.; Mancini, L.; Fox, P.F. Pros and cons for using non-starter lactic acid bacteria (NSLAB) as secondary/adjunct starters for cheese ripening. Trends Food Sci. Technol. 2015, 45, 167-178. [CrossRef]

3. Settanni, L.; Moschetti, G. Non-starter lactic acid bacteria used to improve cheese quality and provide health benefits. Food Microbiol. 2010, 27, 691-697. [CrossRef]

4. Crow, V.; Curry, B.; Hayes, M. The ecology of non-starter lactic acid bacteria (NSLAB) and their use as adjuncts in New Zealand Cheddar. Int. Dairy J. 2001, 11, 275-283. [CrossRef]

5. Di Cagno, R.; De Pasquale, I.; De Angelis, M.; Buchin, S.; Calasso, M.; Fox, P.F.; Gobbetti, M. Manufacture of Italian Caciotta-type cheeses with adjuncts and attenuated adjuncts of selected non-starter lactobacilli. Int. Dairy J. 2011, 21, 254-260. [CrossRef]

6. Bancalari, E.; Montanari, C.; Levante, A.; Alinovi, M.; Neviani, E.; Gardini, F.; Gatti, M. Lactobacillus paracasei 4341 as adjunct culture to enhance flavor in short ripened Caciotta-type cheese. Food Res. Int. 2020, 135, 109284. [CrossRef]

7. Upadhyay, V.K.; Huppertz, T.; Kelly, A.L.; McSweeney, P.L.H. Use of high pressure treatment to attenuate starter bacteria for use as adjuncts for Cheddar cheese manufacture. Innov. Food Sci. Emerg. Technol. 2007, 8, 485-492. [CrossRef]

8. Racioppo, A.; Corbo, M.R.; Piccoli, C.; Sinigaglia, M.; Speranza, B.; Bevilacqua, A. Ultrasound attenuation of lactobacilli and bifidobacteria: Effect on some technological and probiotic properties. Int. J. Food Microbiol. 2017, 243, 78-83. [CrossRef] [PubMed]

9. Di Cagno, R.; De Pasquale, I.; De Angelis, M.; Gobbetti, M. Accelerated ripening of Caciocavallo Pugliese cheese with attenuated adjuncts of selected nonstarter lactobacilli. J. Dairy Sci. 2012, 95, 4784-4795. [CrossRef] [PubMed]

10. Bottari, B.; Levante, A.; Bancalari, E.; Sforza, S.; Bottesini, C.; Prandi, B.; De Filippis, F.; Ercolini, D.; Nocetti, M.; Gatti, M. The Interrelationship Between Microbiota and Peptides During Ripening as a Driver for Parmigiano Reggiano Cheese Quality. Front. Microbiol. 2020, 11, 14. [CrossRef]

11. Peralta, G.H.; Bergamini, C.V.; Audero, G.; Páez, R.; Wolf, I.V.; Perotti, M.C.; Hynes, E.R. Spray-dried adjunct cultures of autochthonous non-starter lactic acid bacteria. Int. J. Food Microbiol. 2017, 255, 17-24. [CrossRef] [PubMed]

12. Martelli, F.; Cirlini, M.; Lazzi, C.; Neviani, E.; Bernini, V. Edible Seaweeds and Spirulina Extracts for Food Application: In Vitro and In Situ Evaluation of Antimicrobial Activity towards Foodborne Pathogenic Bacteria. Foods 2020, 9, 15. [CrossRef] [PubMed]

13. Bancalari, E.; Martelli, F.; Bernini, V.; Neviani, E.; Gatti, M. Bacteriostatic or bactericidal? Impedometric measurements to test the antimicrobial activity of Arthrospira platensis extract. Food Control 2020, 118, 107380. [CrossRef]

14. Martelli, F.; Favari, C.; Mena, P.; Guazzetti, S.; Ricci, A.; Rio, D.D.; Lazzi, C.; Neviani, E.; Bernini, V. Antimicrobial and Fermentation Potential of Himanthalia elongata in Food Applications. Microorganisms 2020, 8, 15. [CrossRef] [PubMed]

15. Bancalari, E.; Bernini, V.; Bottari, B.; Neviani, E.; Gatti, M. Application of Impedance Microbiology for Evaluating Potential Acidifying Performances of Starter Lactic Acid Bacteria to Employ in Milk Transformation. Front. Microbiol. 2016, 7, 11. [CrossRef] [PubMed]

16. Levante, A.; Bancalari, E.; Tambassi, M.; Lazzi, C.; Neviani, E.; Gatti, M. Phenotypic Diversity of Lactobacillus casei Group Isolates as a Selection Criterion for Use as Secondary Adjunct Starters. Microorganisms 2020, 8, 128. [CrossRef] [PubMed]

17. Bancalari, E.; D’Incecco, P.; Savo Sardaro, M.L.; Neviani, E.; Pellegrino, L.; Gatti, M. Impedance microbiology to speed up the screening of lactic acid bacteria exopolysaccharide production. Int. J. Food Microbiol. 2019, 306, 10. [CrossRef] [PubMed] 
18. Bottari, B.; Santarelli, M.; Neviani, E.; Gatti, M. Natural whey starter for Parmigiano Reggiano: Culture-independent approach. J. Appl. Microbiol. 2010, 108, 1676-1684. [CrossRef]

19. Gatti, M.; Bernini, V.; Lazzi, C.; Neviani, E. Fluorescence microscopy for studying the viability of micro-organisms in natural whey starters. Lett. Appl. Microbiol. 2006, 42, 338-343. [CrossRef] [PubMed]

20. Santarelli, M.; Bottari, B.; Lazzi, C.; Neviani, E.; Gatti, M. Survey on the community and dynamics of lactic acid bacteria in Grana Padano cheese. Syst. Appl. Microbiol. 2013, 36, 593-600. [CrossRef]

21. Blaya, J.; Barzideh, Z.; LaPointe, G. Symposium review: Interaction of starter cultures and nonstarter lactic acid bacteria in the cheese environment. J. Dairy Sci. 2018, 101, 3611-3629. [CrossRef]

22. Guarrasi, V.; Sannino, C.; Moschetti, M.; Bonanno, A.; Di Grigoli, A.; Settanni, L. The individual contribution of starter and non-starter lactic acid bacteria to the volatile organic compound composition of Caciocavallo Palermitano cheese. Int. J. Food Microbiol. 2017, 259, 35-42. [CrossRef]

23. Sarada, D.V.L.; Sreenath Kumar, C.; Rengasamy, R. Purified C-phycocyanin from Spirulina platensis (Nordstedt) Geitler: A novel and potent agent against drug resistant bacteria. World J. Microbiol. Biotechnol. 2011, 27, 779-783. [CrossRef]

24. Bottari, B.; Levante, A.; Neviani, E.; Gatti, M. How the Fewest Become the Greatest. L. casei's Impact on Long Ripened Cheeses. Front. Microbiol. 2018, 9, 6. [CrossRef]

25. Gatti, M.; Bottari, B.; Lazzi, C.; Neviani, E.; Mucchetti, G. Invited review: Microbial evolution in raw-milk, long-ripened cheeses produced using undefined natural whey starters. J. Dairy Sci. 2014, 97, 19. [CrossRef] [PubMed]

26. Carafa, I.; Stocco, G.; Franceschi, P.; Summer, A.; Tuohy, K.M.; Bittante, G.; Franciosi, E. Evaluation of autochthonous lactic acid bacteria as starter and non-starter cultures for the production of Traditional Mountain cheese. Food Res. Int. 2019, 115, 209-218. [CrossRef]

27. Kumar, V.; Bhatnagar, A.K.; Srivastava, J.N. Antibacterial activity of crude extracts of Spirulina platensis and its structural elucidation of bioactive compound. J. Med. Plants Res. 2011, 5, 7043-7048. [CrossRef]

28. Golmakani, M.-T.; Soleimanian-Zad, S.; Alavi, N.; Nazari, E.; Eskandari, M.H. Effect of Spirulina (Arthrospira platensis) powder on probiotic bacteriologically acidified feta-type cheese. J. Appl. Phycol. 2019, 31, 1085-1094. [CrossRef]

29. Gabr, G.A.; El-Sayed, S.M.; Hikal, M.S. Antioxidant Activities of Phycocyanin: A Bioactive Compound from Spirulina platensis. J. Pharm. Res. Int. 2020, 32, 73-85. [CrossRef]

30. Martelli, F.; Alinovi, M.; Bernini, V.; Gatti, M.; Bancalari, E. Arthrospira platensis as Natural Fermentation Booster for Milk and Soy Fermented Beverages. Foods 2020, 9, 15. [CrossRef] [PubMed]

31. Martelli, F.; Cirlini, M.; Lazzi, C.; Neviani, E.; Bernini, V. Solid-State Fermentation of Arthrospira platensis to Implement New Food Products: Evaluation of Stabilization Treatments and Bacterial Growth on the Volatile Fraction. Foods 2021, 10, 67. [CrossRef] [PubMed] 